\title{
CHEMOPREVENTIVE POTENTIAL OF SPIRULINA PLATENSIS IN TONGUE CARCINOGENESIS INDUCED BY 4-NITROQUINOLINE-1-OXIDE IN RATS (HISTOLOGICAL AND IMMUNOHISTOCHEMICAL STUDY)
}

\author{
Elham F. Mahmoud ${ }^{*}$ and Tahany Haggag**
}

\begin{abstract}
Objective: The utility of natural, synthetic, or biological chemical factors that hide or inhibit carcinogenic incidence is the aim of cancer chemoprevention. One of the food items that play an important role in cancer chemoprevention is Spirulina platensis (blue green alga). Until now, there is relatively little information on the cancer chemopreventive role of Spirulina platensis ( $\mathrm{Sp}$ ) in animal researches. So, the squamous cell carcinoma can be induced by using 4-nitroquinoline-1 oxide (4-NQO) in tongue mucosa of rats and the chemopreventive efficiency of Spirulina platensis regarding the oral carcinogenesis was examined.
\end{abstract}

Materials and methods: 30 healthy albino rats were equally divided into 3 groups. Group I (rats received normal saline) served as control, Rats of both group II and III received $50 \mathrm{ppm} 4 \mathrm{NQO}$ daily in drinking water for 20 weeks. Spirulina platensis was orally administered to rats of group III at a dose of $300 \mathrm{mg} / \mathrm{kg}$ body weight, once daily via gastric tube. After 20 weeks of drugs administrations, the histopathological changes were evaluated microscopically. Furthermore, by using the image analyser computer system, the anticarcinogenic potential of Spirulina platensis was examined through the immunohistochemical expressions of cytokeratin 5 in tongue specimens.

Results: oral administration of Spirulina platensis considerably reduced the frequency of 4-NQO produced tongue carcinogenesis. A lower percentage of cytokeratin5 immunoexpression was registered in the Spirulina platensis treated group when compared to the carcinogenic group.

Conclusion: our results demonstrated that Spirulina platensis can exert chemopreventive effect against tongue carcinogenesis through suppression of cell propagation and promotion of cell adherence.

KEYWORDS: Tongue carcinogenesis, 4-Nitroquinoline-1-oxide, Chemoprevention, Spirulina platensis, Rats.

* Associate Professor, Department of Oral Biology, Faculty of Oral and Dental Medicine, Suez Canal University, Egypt

** Associate Professor, Department of Oral Biology, Faculty of Oral and Dental Medicine, Cairo University, Egypt 


\section{INTRODUCTION}

Oral tumor is a widespread neoplasm throughout the world, predominately in developing nations, that it comprises up to $25 \%$ of all cancer types. ${ }^{[1]}$ One of the malignant neoplasm is the oral cancer that has high mortality and morbidity rate. ${ }^{[2]}$ Squamous cell carcinoma (SCC) is approximately $90 \%$ of oral cancer, which most commonly invades the tongue. $^{[3]}$

Several carcinogenic materials have been used for chemical induction of cancer in rats. The most widely used material is 4-nitroquinoline 1-oxide (4NQO).$^{[4,5]}$

4 Nitroquinoline-1-oxide (4NQO) is a watersoluble quinoline derivative, and a potent carcinogenic agent in various body organs. When administered 4NQO via drinking water in low concentrations, it can induce tongue squamous cell carcinoma. ${ }^{[6]}$ The resulting morphological features and pathological changes match those seen of human tongue squamous cell carcinoma during its progression. ${ }^{[7]}$ So, for discussing the early events in oral carcinogenesis, $4 \mathrm{NQO}$ induced rat tongue SCC was the best choice model ${ }^{[8,9]}$ and excellent to explore the natural and synthetic agents for chemopreventive efficacy. ${ }^{[10-12]}$

Cancer prevention by using biological, pharmacological, and nutritional interference is the main target of chemoprevention investigate that offers a promising treatment for oral cancer ${ }^{[13,14]}$ Herbal therapy undertakes a necessary portion in pharmaceutical medication for a prolonged time because of their low cost and minimal side effects. ${ }^{[15]}$

Evidence from Epidemiological studies have indicated that consumption of certain diet elements like blue green algae spirulina platensis is associated with lower incidence of cancers. ${ }^{[16,17,18]}$ Spirulina platensis $(\mathrm{Sp})$ is a filamentous blue green alga that is one of the Oscillatoriaceae family. Sp is mostly found in tropical and semitropical countries of cozy alkaline water. Spirulina is recognized by elevated nutritional amount where it rich in proteins
(60-70\% by dry weight), amino acids, multiple vitamins, gamma-linoleic acid, and minerals. ${ }^{[19]}$ The using of spirulina as a nutritional supplement has health advantages in managing or prohibiting hyperglycerolemia, hypercholesterolemia [20], inflammation, overweight ${ }^{[21]}$, cancer ${ }^{[22]}$, and cardiovascular disease ${ }^{[23]}$. Moreover, the antidiabetic effect of Spirulina ${ }^{[24]}$, radio preventive efficacy ${ }^{[25]}$ and a powerful protective for the testicular tissue damage by oxidative stresses resulted from the heavy metals. ${ }^{[26]}$ This encouraged us to assess the power of these blue green algae in the oral cancer chemoprevention. Therefore the current work was designed to investigate the chemopreventive power of the spirulina platensis (SP) versus 4-Nitroquinoline-1-Oxide (4-NQO) induced tongue carcinogenesis in rats through quantitative evaluation of the cytokeratin immunoexpression.

\section{MATERIALS AND METHODS:}

\section{Chemicals}

4-nitroquinoline 1-oxide (4NQO) was obtained from Sigma Company in the form of powder and dissolved in the drinking water for rats of groups (II, III) to a definite concentration of $0.05 \mathrm{~g} / 1$ (50ppm), so the drinking water was replaced one time per week. Spirulina platensis (SP) is a bright, bluegreen tablet with a specific odour. It was purchased from (iHerb.com).

\section{Experimental design}

A total of thirty healthy male albino rats were used in this study. Rats were protected under accurate temperature $\left(24 \pm 2^{\circ} \mathrm{C}\right)$, light-dark periods of 12 hours and with free access to standard commercial diet and drinking water in an air conditioned room. The experimental method was performed in submission with ethical principles for animals' research and undertaken by approval of the institutional guidelines of Faculty of Medicine, Cairo University. After one week of acclimation, rats were randomly divided into three groups (10 rats each). 
Group I (Control): Rats received normal saline and act as a control group.

Group II (4NQO): Rats administered 50 ppm 4 NQO daily in drinking water for 20 weeks. ${ }^{[27]}$

Group III (Sp): Rats in this group were orally administered Spirulina platensis once daily at the same time of cancer induction, via gastric tube at a dose of $300 \mathrm{mg} / \mathrm{kg}$ body weight (dissolved in distilled water). ${ }^{[28,29]}$

\section{Histopathological analysis}

By the end of the experimental period, the rats were sacrificed. The tongue was longitudinally bisected into two halves; each half was subjected to fixation in buffered formalin (10\%) then embedding in paraffin blocks. Sections of $4 \mu \mathrm{m}$ thickness were made for routine histopathological examination with haematoxylin and eosin (H\&E), then examined under light microscope. ${ }^{[30]}$

\section{Immunohistochemistry}

Deparaffinisation of the $4 \mu \mathrm{m}$ tongue sections in three changes of xylene was done, then rehydration in a graded series of ethanol to distilled water was performed. The slides were placed in 0.01 $\mathrm{M}$ citrate-buffer $\mathrm{pH} 6.0$ and heated in a steamer for $30 \mathrm{~min}$ for antigen retrieval. Incubation in 3\% hydrogen peroxide for $20 \mathrm{~min}$ at room temperature. Immunohistochemical staining was performed by using streptavidin-biotin peroxidase method ${ }^{[31]}$

For Immunohistochemical evaluation of cytokeratin, the epithelial cells with brown staining cytoplasm were considered cytokeratin-positive cells. ${ }^{[32]}$ The cytokeratin positive cells in 100 basal and suprabasal cells of the tongue were counted in five high-power fields. The average percentage of cytokeratin-positive cells and its standard deviation value for each group were obtained. The cytokeratin immunoreactivity was measured in the form of an area and area percent in a standard measuring frame per 10 fields using the magnification $400 \mathrm{X}$ by light microscopy transferred to the monitor. The areas of the most intense staining were masked by a blue binary colour that could be measured by the computer system.

\section{Statistical Analysis:}

The measured values were expressed as mean \pm standard deviation. The data were analysed statistically using the analysis of variance (ANOVA) test was used to compare the mean immunostaining intensity values of Cytokeratin 5 between the control and the experimental groups. All statistical calculations were done using computer programs SPSS (Statistical Package for the Social Science; SPSS Inc., Chicago, IL, USA) version 15 for Microsoft Windows. A p value below 0.05 was considered significant.

\section{RESULTS}

\section{Histopathological Findings:}

Group I (Control): Histopathological examination of control group showed that the normal tongue mucosa is covered by keratinized stratified squamous epithelium. Normal filliform papillae could be detected. The underlying connective tissue stroma was composed of fibroblasts, collagen fibers, and few blood vessels. Beneath the lamina propria, groups of well formed striated muscles were also observed (Fig, 1).

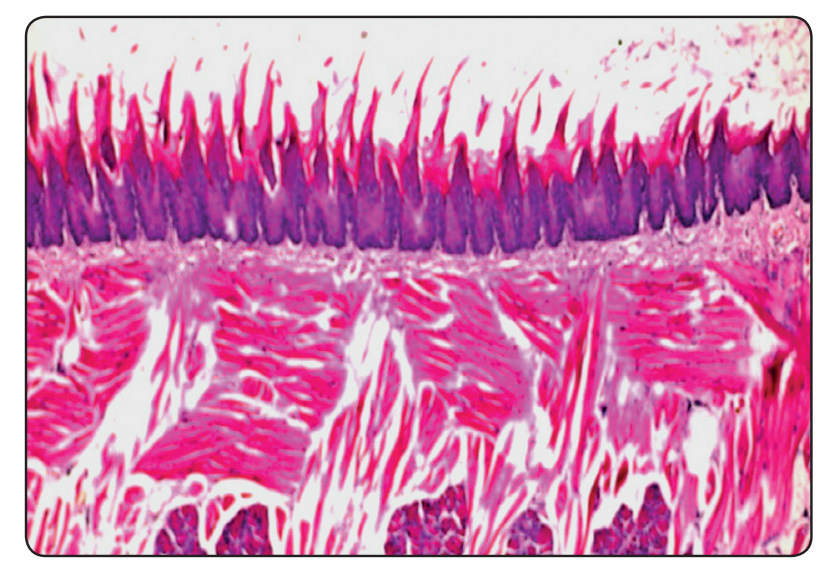

Fig. (1) Photomicrograph showing normal tongue mucosa covering the dorsal surface of the tongue, group I (Control).H\&E $\times 200$. 


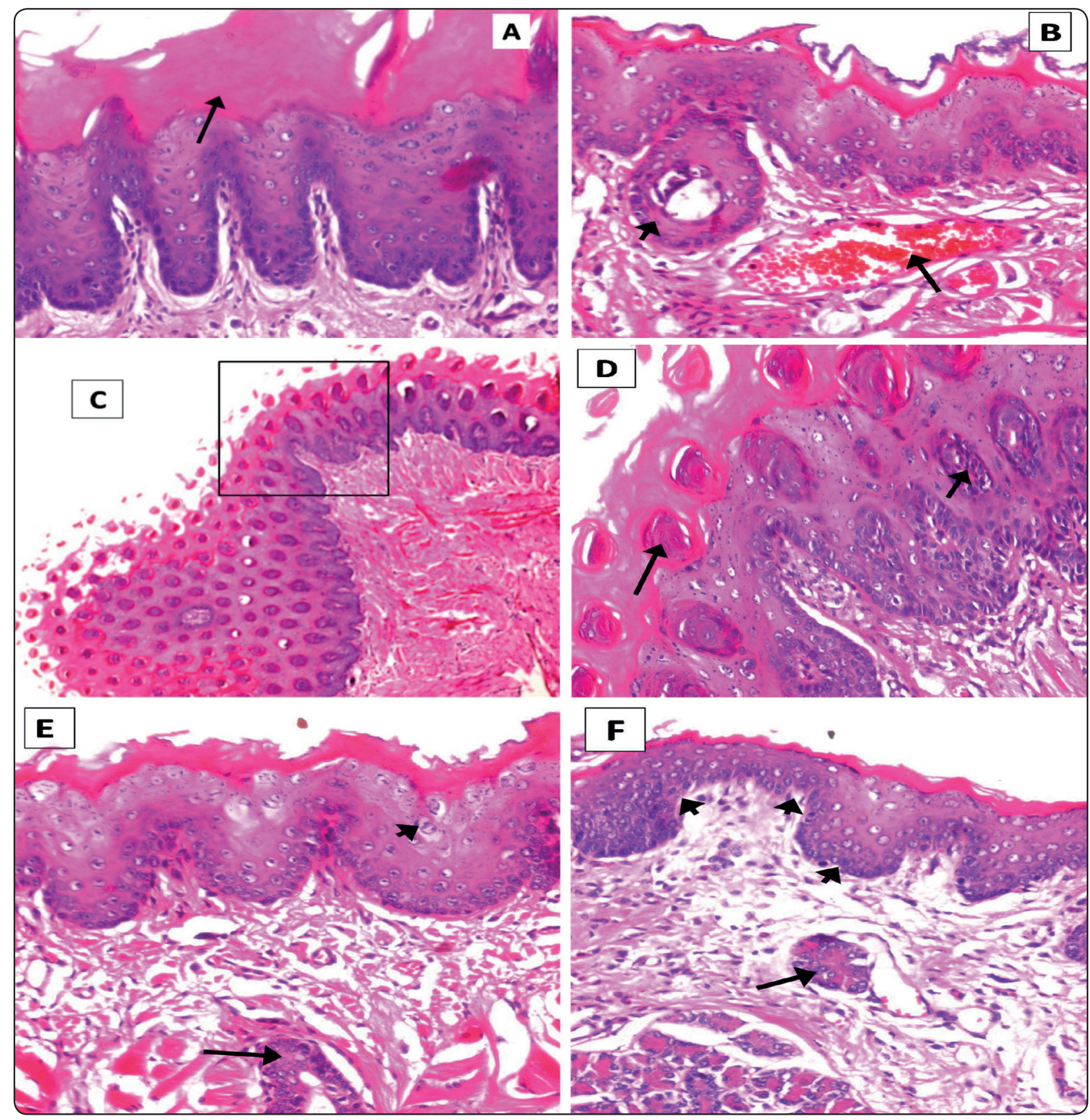

Fig. (2) Group II (4NQO): (A) hyperplastic and hyperkeratinized (arrow) stratified squamous epithelium of dorsal surface covering connective tissue. (B) Epithelium lining the ventral surface showing hyperchromatism, basilar hyperplasia, and alteration in N/C ratio, invasion of neoplastic epithelial cells into the subepithelial tissues (short arrow). The underlying connective tissue showing dilated blood vessel engorged with blood (arrow) and infiltrated with inflammatory cells. (C) Hyperkeratosis, acanthosis of the dorsal surface epithelium. (D) High magnification of epithelium showing multiple keratin pearls and cell nests (long, short arrows). (E) Covering epithelium of ventral surface showing dysplastic features in form of loss of cellular adhesion, basilar hyperplasia, hyperchromatism, and increased mitotic figures (arrow head) with appearance of epithelial nests in underlying connective tissue (arrow). (F) Discontinuity of the basement membrane (arrow heads), and invasion of cell nests in the underlying connective tissue (arrow), $\mathrm{H} \& \mathrm{E} \times 200$. 
Group II (4NQO): light microscopic examination of the tongue's sections of 4NQO treated rats showed evidence of hyperkeratosis, acanthosis and signs of dysplasia in the different layers of the epithelial covering the dorsal surface of the rat' tongue. Few inflammatory cells were included in the underlying connective tissue. Evidence of carcinogenesis in the form of well differentiated squamous cell carcinomas recognized by the spreading of tumor epithelial cells into the subepithelial tissues. Tumor cells having hyperchromatic, pleomorphic nuclei displayed changed nuclear/cytoplasmic ratio, discontinuous basement membrane. The tumor cells disseminated into the underlying submucosa and muscle fibres of the tongue, resulting in small nests with typical keratin pearl formation (Fig.2).

Group III (Sp): Spirulina platensis considerably reduced the incidence of squamous cell carcinoma. Histological examination showed that the epithelium covering the dorsal and ventral surface of tongue mucosa of rats treated with spirulina platensis restored its integrity and revealed marked improvement (Fig. 3).

\section{Immunohistochemical findings:}

Group I: Examination of tongue sections of control rats incubated with cytokeratin monoclonal antibody (CK 5) revealed strongly positive reaction (dark brown) of the cytoplasm of both basal, suprabasal layers of the epithelial cells, while moderately positive cytokeratin expression in the keratin layer. Negative cytokeratin expression in the underlying connective tissue.

Group II: marked reduction in CK 5 immunohistochemical expression in different epithelial layers of tongue sections treated with 4NQO, expressed as weakly to moderately positive CK 5 reaction, with regard to the epithelial nests in the underlying lamina propria.

Group III: Immunohistochemical expression of CK5 of tongue section of Sp treated rats showed the same CK5 staining intensity of the surface epithelium pattern as taken from the control rats (Fig. 4).

\section{Statistical Results:}

Immunohistochemical analysis showed a significantly increased cytokeratin 5 expression in the Spirulina platensis treated group (P-value <0.0009). The mean values are summarised in Table 1 and Fig. 5 for cytokeratin5 expression among the studied groups.

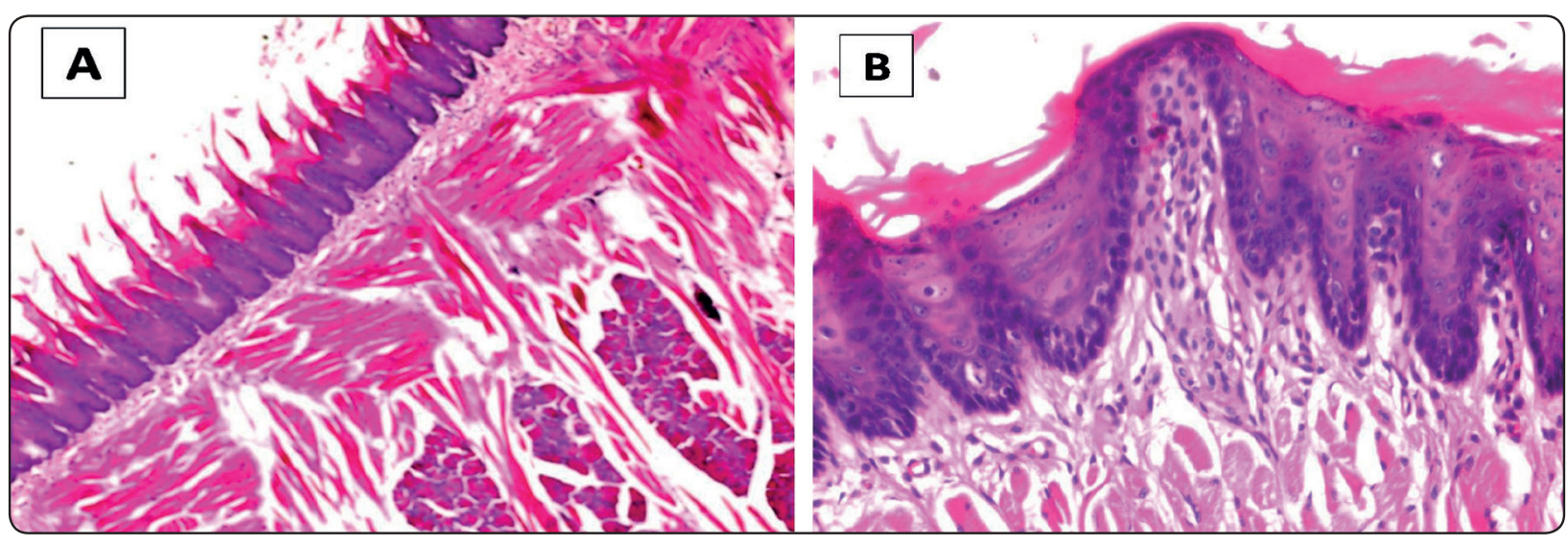

Fig. (3) Photomicrograph of Group III (Sp): showing nearly normal architecture of stratified squamous epithelium covering the dorsal surface (A) and ventral surface of tongue (B), H\&E x 200. 


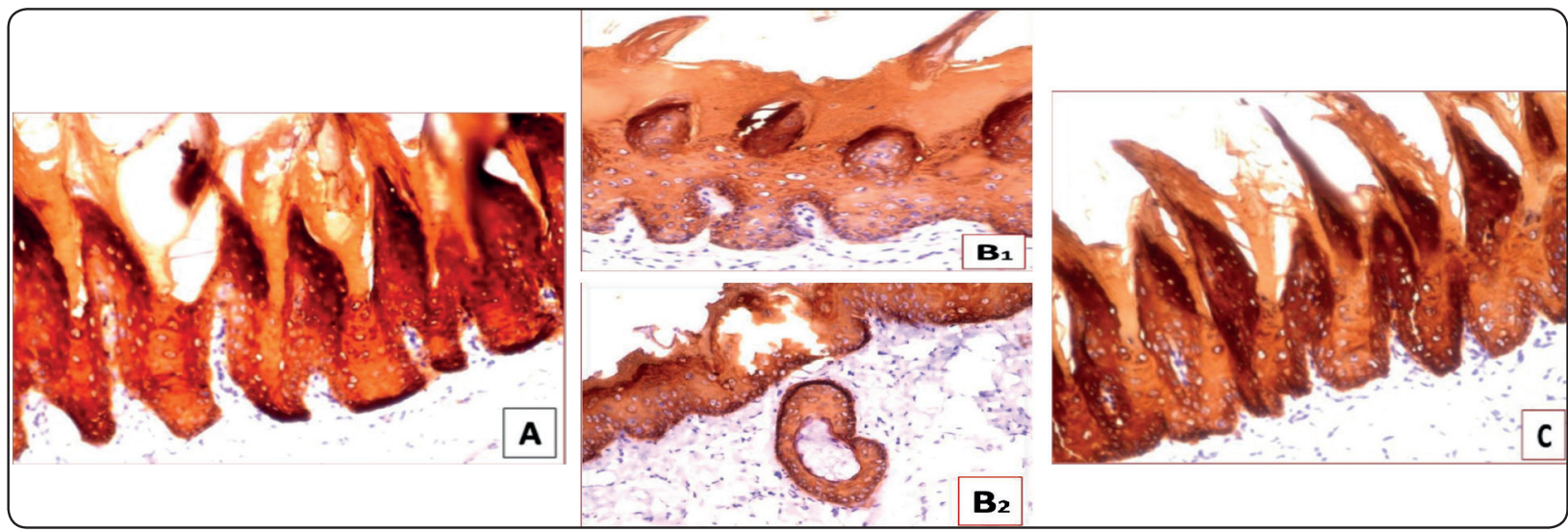

Fig. (4) A photomicrograph of tongue mucosa specimens incubated with anticytokeratin monoclonal antibody revealed: Group I (control) (A): strongly positive CK5 expression in the epithelial cells, and negative expression in the underlying connective tissue. Group II (4NQO) (B1, B2): weakly to moderately positive CK 5 expression. Note: appearance of cell nests in the underlying lamina propria. Group III (Sp) (C): Similar immunohistochemical expression of CK5 to the control group.

TABLE (1) The mean values (mean \pm standard deviation) of cytokeratin5 expression among the studied groups

\begin{tabular}{|c|c|c|c|}
\hline Group & M \pm SD & $\begin{array}{c}\text { F- } \\
\text { value }\end{array}$ & $P$ - value \\
\cline { 1 - 2 } Control (10 rats) & $67.174 \pm 1.414$ & & \\
\cline { 1 - 2 } 4NQO (10 rats) & $54.164 \pm 10.706$ & \multirow{2}{*}{13.01} & \multirow{2}{*}{$0.0009 * *$} \\
\cline { 1 - 2 } 4NQO+SP(10 rats) & $65.801 \pm 4.264$ & & \\
\hline \multicolumn{2}{|c|}{$* *$ Significant difference at $(p<0.001)}$. \\
\hline
\end{tabular}

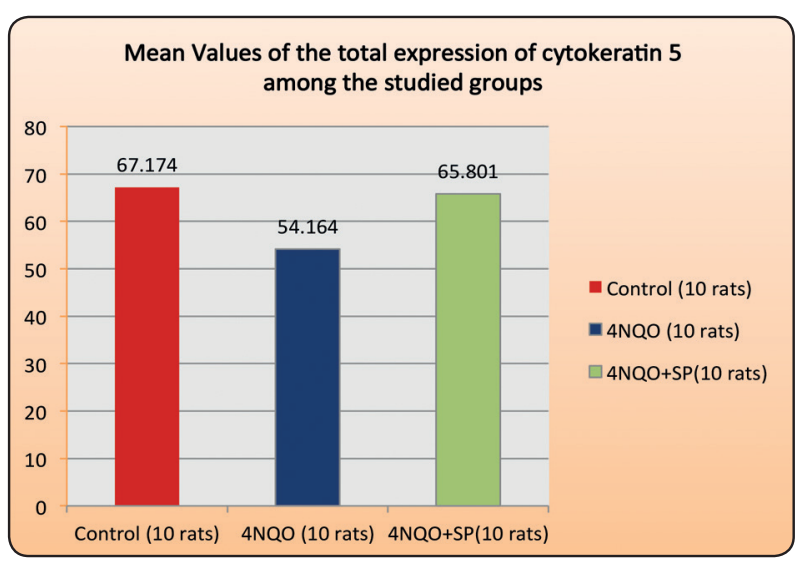

Fig. (5) A bar chart illustrating the statistical difference in the mean values of overall expression of cytokeratin 5 among the studied groups

** $(P$-value $<0.001)=$ highly significant

\section{DISCUSSION}

Carcinogenesis has several stages including initiation, promotion and tumor progression. Several researches have been made to discover a natural or a synthetic compound that could prevent, slow or reverse the process of carcinogenesis, which is known as chemoprevention. Spirulina platensis has been regarded as one of the most promising products used in chemoprevention. ${ }^{[33,34]}$ The current work is considered the first study of the in vivo chemopreventive role of SP against tongue carcinogenesis induced by 4NQO. Our results showed that 4-NQO induced typical carcinogenesis signs and pathological alterations on the tongue epithelium. Our findings coincide that were shown 4-NQO produces squamous cell carcinomas in rats and mice. ${ }^{[6,35]} 4-\mathrm{NQO}$ is a quinoline derivative and water soluble that can result in formation of DNA adduct and also can subject to reduction-oxidation rounding to generate (ROS) reactive oxygen species that leads to DNA strand breaks and mutations. ${ }^{[36]}$ It has been proposed that the efficiency of SP to restrain the carcinogenesis is due to its potent anti-oxidant features that maintain tissues from cell deterioration, significantly reversed the deleterious effects of $4 \mathrm{NQO}$ on tongue epithelium. The Spirulina platensis chemopreventive effect on 
tongue carcinogenesis is symmetrical with preceding records, which were investigated by light and electron microscopy, in which $\mathrm{Sp}$ has been revealed prevention of the incidence of liver carcinogenesis and inhibition of DBN-induced hepatotoxicity. ${ }^{[22,37]}$ Also, SP treated pregnant rats' relieved the brain damage in newly-born rats induced by lead toxicity. ${ }^{[38]}$ As well as pre-treatment with SP might exhibit a role in decreasing the effect of cadmium toxicity due to the protective effect of its antioxidant properties that detected by the lowering of MDA and NO in addition to the increasing of GSH and SOD levels in liver tissue. ${ }^{[39]}$ It has been reported that Spirulina was considered as normal origin of proteins, carotenoids and other micronutrients when used in daily diets of natives in Africa and America. Spirulina contains various phytopigments (carotenoids, chlorophyll, and phycocyanin). ${ }^{[40]}$ So it can increase the efficiency of the enzymes that are concerned with the antioxidants as catalase, superoxide dismutase, glutathione reductase and glutathione peroxidase significantly. Apart from that, Spirulina contains phenolic acids, tocopherols and bcarotene that are known to exhibit antioxidant properties. ${ }^{[41]}$ In addition to studies reported that Spirulina has been documented to be efficient versus the free radicals induced cellular transformation. ${ }^{[42]}$ Therefore, in our study, the antioxidants found in Spirulina platensis might explain how to maintain the endogenous antioxidants and inhibit elevation of oxidative stress, thus relieving the pathological changes induced by $4 \mathrm{NQO}$ in tongue epithelium. An important issue must be taken into consideration regarding the chemopreventive inhibitory role of Spirulina on tongue carcinogenesis; it exactly differs according to many variables; Spirulina doses, shapes and modes of administration, tumor induction procedure.

In the present work, the induction of tongue carcinogenesis was accompanied with decreased immunohistochemical expression of cytokeratin 5. Cytokeratins (CKs) are the major proteins of the intermediary filaments of keratin, located in the cytoplasm and represent an important part of the cytoskeleton of all epithelial cells ${ }^{[43,44]}$ and it has been observed that changes in CK expression patterns leads to the altered expression of numerous genes and proteins in different organ systems. ${ }^{[45]}$ The strong CK5 expression in the epithelial cells of tongue mucosa from the control and Spirulina platensis treated rats; insured that CK5 play a major role in cell to cell contact, anchoring the nucleus within the cell maintaining its structural integrity, while the weakly immunohistochemical expression of CK5 in the tongue specimens of 4NQO treated rats that results in carcinogenic transformation in the form of squamous cell carcinoma as observed by light microscope. These results could be explained as any deviation from the normal might affect the whole tissue adversely and decrease the cytokeratin reactivity in the different epithelial cells. Our results coincides with other studies reported that Ck5 expression is diminished at the stratum spinosum level of the normal and in the dysplastic epithelium of the oral mucosa. Cytokeratins furnish mainly as tumor markers for diagnostic methods in case of cancers. ${ }^{[46]}$ Regarding the prognostic value of these proteins, the results of the current work are parallel to former researches that revealed a reduced cytokeratin CK5 expression was associated with malignant transformation; but, the CK5 expression did not stop entirely. ${ }^{[47]}$ In comparison to other study reported an elevated CK5 expression in $81 \%$ of squamocellular carcinomas that were involved in their work, with strong CK5 immunoexpression, that was spreaded in the most of the tumoral cells. ${ }^{[48]}$ These findings denote anti-invasive effect and promoted cellular adhesion as a recent technique for the chemopreventive role of Spirulina platensis. Therefore additional studies are required for improved understanding of the effectiveness of this naturally occurring blue green algae Spirulina platensis to make sure of these observations and optimistically to emphasize their potential in oral cancer chemoprevention. 


\section{REFERENCES}

1. Magrath I , Litvak J. 1993. Cancer in developing countries: opportunity and challenge. J Natl Cancer Inst; 85: 862-874.

2. Stewart, B.W. and C.P. Wild, 2014. World Cancer Report 2014. International Agency for Research on Cancer (IARC) Nonserial Publication.

3. Macfarlane GJ, Zheng T, Marshall JR, et al. 1995: Alcohol, tobacco, diet and the risk of oral cancer: a pooled analysis of three case-control studies. Eur J Cancer B Oral Oncol; 31B: 181-187.

4. Tanaka, T. and R. Ishigamori, 2011. Understanding carcinogenesis for fighting oral cancer. Journal of Oncology, pp: 603740 .

5. Dayan, D., Kaplan, I., Russack, S., Bodner, L (1997): Dysplastic changes of the palate and tongue mucosa induced by topically applied 4 nitro-quinoline-N-oxide 4NQO) in desalivated rats. In: Harris, M.; Johnson, N. \& Varma, A. K. (eds.). Oral oncology. Proceedings of the 5th International Congress on Oral Cancer. London, MacMillan India Ltd., pp.514-7.

6. El-Rouby, D. H. (2011): Histological and immunohistochemical evaluation of the chemopreventive role of lycopene in tongue carcinogenesis induced by 4-nitroquinoline-1-oxide. Arch. Oral Biol.; 56:664-71 2011.

7. Ribeiro DA, Favero Salvadori DM, da Silva RN, Ribeiro Darros B, Alencar Marques, ME. 2004: Genomic instability in nonneoplastic oral mucosa cells can predict risk during 4- nitroquinoline 1-oxide-induced rat tongue carcinogenesis. Oral Oncol; 40: 910-5.

8. Kaplan I, Hochstadt T, Dayan D. PCNA in palate and tongue mucosal dysplastic lesions induced by topically applied 4NQO in desalivated rat. Med Oral 2002; 7:336 43.

9. Tanuma J, Shisa H, Hiai H, Higashi S, Yamada Y, Kamoto $\mathrm{T}$, et al. Quantitative trait loci affecting 4-nitroquinoline 1- oxide-induced tongue carcinogenesis in the rat. Cancer Res 1998; 58: 1660-4.

10. Nishimura A. Changes in Bcl-2 and Bax expression in rat tongue during 4-nitroquinoline 1-oxide-induced carcinogenesis. J Dent Res 1999; 78:1264-9.

11. Shiotani H, Denda A, Yamamoto K, Kitayama W, Endoh T, Sasaki Y, et al. Increased expression of cyclooxygenase-2 protein in 4-nitroquinoline-1-oxide induced rat tongue carcinomas and chemopreventive efficacy of a specific inhibitor, nimesulide. Cancer Res 2001; 61:1451-6.
12. Tanaka T, Kohno H, Nomura E, Taniguchi H, Tsuno T, Tsuda H. 2003: A novel geranylated derivative, ethyl 3-(40-geranyloxy-30- methoxyphenyl)-2-propenoate, synthesized from ferulic acid suppresses carcinogenesis and inducible nitric oxide synthase in rat tongue. Oncology; 64: 166-75.

13. Glenn M.P., Kahnberg P., Boyle G.M., Hansford K.A., Hans D., Martyn A.C., Parsons P.G., Fairlie D.P., 2004: Antiproliferative and phenotype-transforming antitumor agents derived from cysteine, J. Med. Chem. 47 ; 2984 2994.

14. Swanson H.I., Njar V.C., Yu Z., Castro D.J., Gonzalez F.J., Williams D.E., Huang Y., Kong A.N., Doloff J.C., Ma J., Waxman D.J., Scott E.E., 2010: Targeting drug metabolizing enzymes for effective chemoprevention and chemotherapy, Drug Metab. Dispos. 38: 539-544.

15. Ogbera AO., Dada O., Adeyeye F., Jewo PI. 2010: Complementary and alternative medicine use in diabetes mellitus. West Afr J Med.; 29: 158-162.

16. Amha Belay. 2002: The potential applications of Spirulina (Arthrospira) as a nutritional and therapeutic supplement. J. American. Neutraceutical Association (Spring, 2002), $5(2), 27-48$.

17. Abdulmumin A. Nuhu. 2013: Spirulina (Arthrospira): An Important Source of Nutritional and Medicinal Compounds, Journal of Marine Biology, Article ID 325636, 8.

18. Akao, Y., Ebihara, T. \& H. Masuda et al., 2009: "Enhancement of antitumor natural killer cell activation by orally administered Spirulina extract in mice," Cancer Science, 100 (8), 1494-1501.

19. Hosseini SM, Khosravi-Darani K, Mozafari MR. 2013: Nutritional and medical applications of spirulina microalgae. Mini Rev Med Chem.; 13: 1231-1237.

20. Deng R, Chow TJ. 2010: Hypolipidemic, antioxidant, and antiinflammatory activities of microalgae Spirulina. Cardiovasc Ther.; 28: 33-45.

21. Coskun ZK, Kerem M, Gurbuz N, Omeroglu S and Pasaoglu H. 2011: The study of biochemical and histopathological effects of Spirulina in rats with TNBS-induced colitis. Bratislavske Lekarske Listy.; 112: 235-243.

22. Ismail MF, Ali DA, Fernando A, Abdraboh ME, Gaur RL, Ibrahim WM, et al. 2009: Chemoprevention of rat liver toxicity and carcinogenesis by Spirulina. Int J Biol Sci.; 5: 377-387. 
23. Khan M, Shobha JC, Mohan IK, Naidu MU, Sundaram C, Singh S, et al. 2005: Protective effect of Spirulina against doxorubicin-induced cardiotoxicity. Phytother Res.; 19: 1030-1037.

24. Karkos PD, Leong SC, Karkos CD, Sivaji N, Assimakopoulos DA. 2011: Spirulina in clinical practice: evidencebased human applications. Evid Based Complement Alternat Med.; 2011: 531053.

25. Wafaa A M, Shimaa A I, Yasmina MA. 2014: Spirulina platensis ameliorative effect against GSM 900-MHz cellular phone radiation-induced genotoxicity in male SpragueDawley rats. Comp Clin Pathol.; 23: 1719-1726.

26. Samir AE B, Sally A E, Hossam E, Ibrahim M A. 2016: Antioxidant potential of Spirulina platensis mitigates oxidative stress and reprotoxicity induced by sodium arsenite in male rats. Oxid Med Cell Longev: 1-8.

27. Lawahez M.I., Nevien M.A., Heba A.S. 2016: Anticarcinogenic effect of biopropolis on chemically induced tongue cancer in albino rats. Aust J Basic \& App Sci.; 10(8): 173-180.

28. Simsek N., Karadeniz A., Kalkan Y., Keles O. N., and Unal B., 2009: "Spirulina platensis feeding inhibited the anemia- and leucopenia-induced lead and cadmium in rats," Journal of Hazardous Materials, vol. 164, no. 2-3, pp. 1304-1309.

29. Shimaa A.A.I., 2017: Ameliorative potential of spirulina platensis against lead acetate induced immuno-suppression and kidney apoptosis in rats. Ann Clin Pathol 5(5): 1120.

30. Suvarna S K, Layton C, Bancroft J D. 2013: Bancroft's Theory and Practice of Histological Techniques. Elsevier, Churchill Livingstone.

31. Hsu, S.M., Raine, L. and Fanger, H. 1981: A comparative study of the peroxidaseantiperoxidase method and an avidin-biotin complex method for studying polypeptide hormones with radioimmunoassay antibodies. Am. J. Clin. Pathol., 75:734-738.

32. Samia M.S, Mahmoud A.B, Omar I. G. and Hassan F.A., 2011: Histopathological and immunohistochemical studies on the adrenal cortical tumors of Egyptian patients. Life Sci J.; 8(4): 970-978.

33. Mathew B, Sankaranarayanan R, Nair PP et al., 1995: Evaluation of chemoprevention of oral cancer with Spirulina fusiformis. Nutr Cancer; 24:197-202
34. Nikte Y., Martinez P., Gloria D.O., Cristian J.M., Eduardo M.B., Isela A.G., 2017: Chemopreventive and antioxidant effect of polyphenol free Spirulina maxima and Its hydrolyzed protein content: Investigation on azoxymethane treated mice. Pharmacogn. Mag. 13(50): 164-169.

35. Tanaka T, Kojima T, Okumura A, Yoshimi N, Mori H., 1991: Alterations of the nucleolar organizer regions during 4-nitroquinoline 1-oxide-induced tongue carcinogenesis in rats. Carcinogenesis; 12: 329-33.

36. Phillips DH. 2002: Smoking-related DNA and protein adducts in human tissues. Carcinogenesis; 23: 1979-2004.

37. Khan Z, Bhadouria P, Bisen PS. 2005: Nutritional and therapeutic potential of Spirulina. Curr Pharm Biotechnol; 6:373-379

38. Gargouri M, Ghorbel-Koubaa F, Bonenfant-Magne M, Magne C, and Dauvergne X, et al. (2012): Spirulina or dandelion-enriched diet of mothers alleviates lead-induced damages in brain and cerebellum of newborn rats. Food Chem Toxicol 50: 2303-2310.

39. Karadeniz A, Cemek M, Simsek N (2009): The effects of Panax ginseng and Spirulina platensis on hepatotoxicity induced by cadmium in rats. Ecotoxicol Environ Saf 72: 231-235.

40. Pak W, Takayama F, Mine M, Nakamoto K, Kodo Y, Mankura M, et al. 2012: Anti oxidative and anti-inflammatory effects of Spirulina on rat model of non-alcoholic steatohepatitis. J Clin Biochem Nutr; 51(3): 227-34.

41. Ravi M, De Lata S, Azharuddin S, Paul SFD. 2010: The beneficial effects of Spirulina focusing on its immunomodulatory and antioxidant properties. Nutr Diet Suppl; 2: 73-83.

42. Upasani CD, Khera A, Balaraman R. 2001: Effect of lead with vitamin E, C, or Spirulina on malondialdehyde, conjugated dienes and hydroperoxides in rats. Indian J Exp Biol; 39:70-74

43. Schweizer J, Bowden PE, Coulombe PA, Langbein L, Lane EB, Magin TM, Maltais L, Omary MB, Parry DA, Rogers MA and Wright MW. 2006: New consensus nomenclature for mammalian keratins. J Cell Biol 174: 169174.

44. Fillies T, Jogschies M, Kleinheinz J, Brandt B, Joos U and Buerger H, 2007: Cytokeratin alteration in oral leukoplakia and oral squamous cell carcinoma. Oncol Rep 18: 639643. 
45. Thiel UJ, Feltens R, Adryan B, Gieringer R, Brochhausen C, Schuon R, Fillies T, Grus F, Mann WJ and Brieger J, 2011: Analysis of differentially expressed proteins in oral squamous cell carcinoma by MALDITOF MS. J Oral Pathol Med 40: 369379.

46. Yamamoto Y, Ibusuki M, Nakano M, Kawasoe T, Hiki R and Iwase H, 2009: Clinical significance of basal-like subtype in triple negative breast cancer. Breast Cancer 16: 260267.
47. Marley JJ, Robinson PA and Hume WJ, 1994: Expression on human cytokeratin 14 in normal, premalignant and malignant oral tissue following isolation by plaque differential hybridization. Eur J Cancer B Oral Oncol 30B: 305311.

48. Kaufmann O, Fietze E, Mengs J and Dietel M, 2001: Value of p63 and cytokeratin 5/6 as immunohistochemical markers for the differential diagnosis of poorly differentiated and undifferentiated carcinomas. Am J Clin Pathol 116: 823830 . 